This collection of slides and associated material is a valuable teaching resource that has grown and developed for more than 130 years. The oldest slides have national significance, for instance, slides prepared by New Zealand's first woman medical graduate, Emily Siedeberg. Others tell the story of the growth of the Otago Medical School and the ongoing struggle to teach larger and larger classes. Changing research interests and strong individuals have played a role in developing the character of the collection which is still in very active use. Recently old wax blocks were used in an immuno-histological study into wound-healing.

Teaching histology, has for several decades, revolved around classroom use of microscopes and associated sets of slides. Lately it has become possible to scan slides in detail to make zoomable images that can be reviewed by students on their computers.

10.1016/j.jchb.2009.02.022

\title{
Understanding Old People's burial places: A case study from Ngarrindjeri ruwe, South Australia
}

K. Niland (Department of Archaeology, Flinders University, Adelaide, Australia), K. Domett (School of Veterinary and Biomedical Sciences, James Cook University, Townsville, Qld, Australia), kate.domett@jcu.edu.au, L.A. Wallis (Department of Archaeology, Flinders University, Adelaide, Australia)

At the request of the Ngarrindjeri community, a burial complex located in the Kurangk (Coorong), South Australia, was investigated as a component of a broader conservation program. This involved excavation and on-site analysis of two individuals prior to their reburial and site rehabilitation. The characteristics of age, sex, pathology, trauma and the nature of the burial place itself (incorporating mortuary practices) were analysed and compared with ethnohistorical and contemporary Ngarrindjeri practices. Radiocarbon dating of charcoal associated with one of the burials revealed it had occurred ca. 2200 years ago, and was of an elderly woman. Also present was a secondary reburial of another elderly individual (whose sex could not be ascertained with confidence), offering empirical support for a long-standing tradition of Ngarrindjeri people caring for the burial places of their Old People. Analysis of joint degeneration and dental wear of both individuals also provided evidence for a range of cultural activities including basket weaving, net making and cockle collecting. 